\title{
PEMANFAATAN FESES TERNAK SAPI SEBAGAI ENERGI ALTERNATIF BIOGAS BAGI RUMAH TANGGA DAN DAMPAKNYA TERHADAP LINGKUNGAN
}

\author{
Latifah Hanum Damanik \\ STIKES Surya Global Yogyakarta \\ Email: tipahanum@gmail.com \\ Adi Heru Husodo \\ Fakultas Kedokteran Universitas Gadjah Mada \\ Totok Gunawan \\ Fakultas Geografi Universitas Gadjah Mada
}

\begin{abstract}
Sustainable development is a development that meets the needs of the present without compromising the right to meet the needs of future generations. It is used to describe the development of sustainable improvement in the quality of human life, while trying not to exceed the ability of the ecosystem that supports life. Utilization of waste as an alternative source of energy is not yet common, especially the waste that comes in a large capacity from farming activities. This is because the waste released into the environment has particular characteristics and properties, with potential impacts for environmental disadvantage that needs to be done handling back. This research studied the utilization of cattle feces as an alternative energy of biogas for household and its impact on the environment in Kepuharjo Village, Cangkringan, Sleman. The results give an overview of how the community has responded positively to the use of animal feces biogas as an alternative energy, which proved of value to the utilization of biogas energy savings of 2.50 .
\end{abstract}

Keywords: Utilization of alternative energy biogas

\begin{abstract}
ABSTRAK
Pembangunan berkelanjutan adalah pembangunan yang dapat memenuhi kebutuhan masa kini tanpa mengorbankan hak pemenuhan kebutuhan generasi mendatang. Pembanguan berkelanjutan digunakan untuk mengartikan perbaikan mutu kehidupan manusia dengan tetap berusaha tidak melampaui kemampuan ekosistem yang mendukung kehidupannya. Pemanfaatan limbah sebagai sumber energi alternatif belum merupakan cara yang umum dilakukan, terutama limbah yang bersumber dari kegiatan peternakan dengan kapasitas yang besar sebab limbah yang dibuang ke lingkungan mempunyai sifat dan karakteristik tertentu dan cukup potensial menimbulkan dampak yang merugikan lingkungan sehingga perlu dilakukan penanganan kembali. Pemanfaatan feses ternak sapi sebagai energi alternatif biogas bagi rumah tangga dan dampaknya terhadap lingkungan Di Desa Kepuharjo, Kecamatan Cangkringan, Kabupaten Sleman memberikan gambaran sebuah masyarakat yang sudah merespon secara positif terhadap pemanfaatan feses ternak sebagai energi alternatif biogas
\end{abstract}


hal itu terbukti dari nilai penghematan yang diperoleh dari pemanfaatan energi biogas sebesar $2,50 \mathrm{~m}^{3}$

Kata Kunci: Pemanfaatan energi alternatif biogas, Pembangunan berkelanjutan

\section{PENGANTAR}

Pembangunan adalah upaya untuk mengubah keadaan, dari kondisi tradisional ke modern dari terbelakang ke arah kemajuan, tanpa mengingkari arti penting dari nilai-nilai kemanusiaan yang menjadi landasan utama pembangunan. Dengan kata lain, pembangunan merupakan wahana bagi manusia untuk mencapai peradaban baru yang bersendikan pada nilai-nilai yang khas manusiawi. Pendayagunaan sumber daya alam sebagai modal pokok pembangunan harus dilakukan secara terencana, rasional, optimal, bertanggungjawab dan sesuai dengan kemampuan daya dukungnya dengan mengutamakan kemakmuran rakyat serta memperhatikan kelestarian fungsi dan keseimbangan lingkungan hidup bagi pembangunan yang berkelanjutan.

Dewasa ini sektor pertanian dihadapkan pada kendala semakin terbatasnya ketersediaan sumber daya alam, resiko kemerosotan kualitas sumber daya alam dan dampak eksternalitas negatif dari pertumbuhan ekonomi yang positif. Oleh karena itu, cara pendekatan, strategi dan teknologi tepat guna yang lingkungan secara bertahap merupakan suatu alternatif yang perlu diterapkan bila diinginkan adanya keseimbangan dan keterpaduan prinsip pencapaian produksi dan kelestarian lingkungan. Dengan demikian, dianggap sebagai suatu rangsangan baru, yang perlu disampaikan kepada masyarakat petani melalui kegiatan sosialisasi pertanian. Respon membutuhkan suatu stimulus sebagai rangsangan kepada individu untuk memberikan suatu reaksi. Wujud dari rangsangan itu sendiri dapat bermacam-macam yang akan dimanifestasikan ke dalam sikap dan adopsinya terhadap inovasi tersebut. Pada kenyataannya menunjukan bahwa kemampuan petani di dalam menanggapi suatu teknologi berbeda-beda. Hal ini dipengaruhi oleh beberapa faktor, salah satunya adalah faktor kondisi sosial ekonomi petani. Akan tetapi, sering pertumbuhan dan pengelolaan di bidang peternakan yang dilakukan secara intensif, efek yang dihasilkan juga semakin mengkuatirkan, salah satunya adalah limbah.

Pemanfaatan limbah sebagai sumber energi alternatif belum merupakan cara yang umum dilakukan, terutama limbah yang bersumber dari kegiatan peternakan dengan kapasitas yang besar. Untuk itu, limbah yang dibuang ke lingkungan mempunyai sifat dan karakteristik tertentu dan cukup potensial menimbulkan dampak merugikan pada lingkungan sehingga perlu dilakukan penanganan kembali. Menumpuknya limbah di dalam lingkungan berarti ada kecenderungan menurunnya kualitas lingkungan. Untuk mengantisipasi permasalahan ini, maka kesungguhan mengelola lingkungan hidup makin dirasa penting. Ini mulai jelas terlihat dari konsep "Pembangunan Berwawasan Lingkungan" yang di dalam implementasinya dijabarkan dalam berbagai peraturan perundangundangan yang berkaitan dengan lingkungan hidup. Beberapa di antaranya yang terpenting adalah Undang-undang Republik Indonesia No. 32 Tahun 2009 tentang Perlindungan dan Pengelolaan Lingkungan Hidup. Ini berarti setiap rencana atau kegiatan yang sudah berjalan harus mempertimbagan aspek ekologi agar dampak yang negatif yang ditimbulkan tidak mengganggu fungsi dan peruntukan lingkungan.

Limbah ternak merupakan sisa buangan dari suatu kegiatan usaha peternakan, seperti usaha pemeliharaan ternak, rumah potong hewan, dan pengolahan produk ternak. Limbah tersebut meliputi limbah padat dan limbah cair seperti: faeces urine, sisa makanan, embrio, kulit telur, lemak, darah, bulu, kuku, tulang, tanduk, dan isi rumen. Semakin besar skala usaha, limbah semakin banyak (Djaja, 
2008). Keberadaan limbah menjadi masalah yang sangat serius. Masyarakat di sekitar peternakan akan terganggu. Bukan saja baunya tidak sedap, tetapi keberadaannya juga mencemari lingkungan, mengganggu pemandangan, dan bisa menjadi vektor penyakit.

Masalah yang sering dihadapi oleh masyarakat adalah sampah dan kotoran ternak yang tidak ditanggani. Akibatnya, lingkungan di sekitarnya akan tercemar. Oleh karena itu, diperlukan penanganan yang baik agar baunya tidak timbul, atau tidak meluas. Kotoran ternak jika didiamkan begitu saja akan mengalami penyusutan unsur kimianya. Penyusutan biasa disebabkan oleh penguapan dan pencucian oleh air hujan, angin, panas matahari dan kelembaban lingkungan. Pada dasarnya gangguan yang ditimbulkan oleh limbah ternak dan tanaman dapat diatasi dengan pembuatan sumber energi alternatif seperti biogas, kompos, briket dan sebagainya. Dengan demikian, pengolahan limbah menjadi hal yang serius dan perlu ditanggani segera. Saat ini banyak usaha peternakan yang dilakuan secara intensif sehingga penemuan baru yang digunakan untuk pemanfaatan limbah biologi sedang digalakkan agar para warga pedesaan baik petani maupun peternak mampu mengolahnya sebagai sumber energi alternatif untuk keperluan rumah tangga dari hasil usaha tersebut. Salah satu energi alternatif tersebut adalah biogas.

Biogas dihasilkan dari limbah peternakan dan pertanian yang relatif mudah diperoleh di lingkungan masyarakat pedesaan. Biogas adalah gas yang dapat dihasilkan dari fermentasi faeces (kotoran) ternak misalnya: sapi, kerbau, babi, kambing, ayam, dan lain-lain dalam suatu ruangan yang disebut digester. Sebelum diperkenalkannya teknologi biogas, sebagian besar penduduk wilayah Desa Kepuharjo, Kecamatan Cangkringan, Kabupaten Sleman, mempergunakan kayu bakar dan minyak sebagai energi untuk kebutuhan rumah tangga. Berbagai kondisi tersebut di atas, Desa Kepuharjo dan Desa Umbulharjo, Kecamatan Cangkringan, Kabupaten Sleman dirasa sangat perlu dilakukan berbagai usaha untuk dapat meningkatkan daya dukung lingkungannya. Pada bidang pertanian perlu dilengkapi dengan usaha konservasi tanah dan air, bidang usaha ternak perlu dilakukan usaha-usaha untuk meningkatkan produksi ternak, dan bidang kebutuhan energi untuk rumah tangga perlu dilakukan konversi energi dari kayu dan minyak. Kecukupan energi pada masyarakat, khususnya yang tinggal di pedesaan dapat diatasi dengan menggunakan energi alternatif yang murah, ramah lingkungan, mudah diperoleh, dan dapat diperbaharui.

Penelitian ini ingin menampilkan faktor-faktor yang menyebabkan peternak termotivasimemanfaatkanfesesternaksebagai energi alternatif biogas untuk kebutuhan rumah tangga dan dampak dari pemanfaatan feses ternak sebagai energi alternatif biogas terhadap penghematan pengeluaran rumah tangga dengan menggunakan metode survei, yaitu suatu metode pengambilan sampel (responden) dari suatu populasi dengan menggunakan kuesioner (daftar pertanyaan) sebagai alat pengumpul data primer, yang bersifat deskriptif analitis, yang dimaksudkan untuk memberi gambaran terhadap obyek yang diteliti, serta mengkaji hubungan antar-variabel. Lokasi penelitian yaitu Desa Kepuharjo dan Desa Umbulharjo, Kecamatan Cangkringan, Kabupaten Sleman, Yogyakarta yang selama ini memanfaatkan teknologi biogas sebagai energi alternatif. Penentuan sampel penelitian didasarkan pada pertimbangan bahwa sampel yang diteliti memenuhi kriteria untuk dianalisis. Materi yang dibutuhkan dalam penelitian ini berupa referensi-referensi atau literatur yang relevan dengan obyek penelitian sebagai penunjang data sekunder serta peta administrasi lokasi penelitian. Alat yang dipergunakan dalam penelitian ini berupa: kuesioner untuk mengkaji informasi sebagai 


\section{LATIFAH HANUM DAMANIK, ADI HERU HUSODO, DAN TOTOK GUNAWAN PEMANFAATAN FESES TERNAK SAPI SEBAGAI ENERGI ALTERNATIF BIOGAS BAGI RUMAH TANGGA DAN \\ DAMPAKNYA TERHADAP LINGKUNGAN}

jawaban respoden guna mencapai tujuan penelitian.

Model analisis yang akan digunakan dalam penelitian ini adalah rata-rata, persentase dan kategori, yang dimaksudkan untuk menggambarkan karakteristik umum respoden. Kategorisasi jawaban responden dilakukan dengan pemberian nilai atau skor terhadap setiap item pertanyaan yang diajukan. Adapun nilai skor terdiri atas empat kategori, yaitu (sangat setuju skornya $=4$, setuju skornya $=3$, ragu - ragu $=2$, dan tidak setuju skornya $=1$ ). Adapun langkah-langkah dalam menganalisis penelitian mengenai pemanfaatan feses ternak sapi sebagai energi alternatif biogas bagi rumah tangga dan dampaknya terhadap lingkungan adalah sebagai berikut: analisis faktor-faktor yang berpengaruh terhadap motivasi peternak dalam membangun teknologi biogas (umur, pendidikan, jumlah anggota keluarga, dan pengalaman berternak) dan analisis faktorfaktor keperluan hidup/ sosial ekonomi peternak sebelum dan sesudah membangun teknologi biogas.

Analisis ini menggunakan regresi linier berganda dengan uji korelasi dan Uji beda (uji t) dengan menggunakan program SPSS versi 16.0 terbaru dengan fasilitas komputer, di mana data yang akan digunakan adalah diambil dari data kuesioner yang telah dikumpulkan dari para responden yang di dapat dari Desa Kepuharjo dan Desa Umbulharjo, Kecamatan Cangkringan, Kabupaten Sleman, Yogyakarta. Adapun langkah-langkah perhitungan yang digunakan adalah analisis regresi linier langkah-langkahnya adalah menghitung koefisien korelasi sederhana antara skor butir $(X)$ dengan skor variabel (Y). Perhitungan koefisien korelasi ini menggunakan rumus koefisien sederhana pearson:

$$
r_{\mathrm{xy}}=\frac{N \sum X Y-\left(\sum X\right)\left(\sum Y\right)}{\sqrt{\left\{N \sum X^{2}-\left(\sum X\right)^{2}\right\}\left\{N \sum Y^{2}-\left(\sum Y\right)^{2}\right\}}}
$$

dengan:

$r_{x y}=$ Koefisien korelasi antara skor butir (X) dengan skor butir (Y)

$\mathrm{N}=$ Jumlah responden uji coba

$\mathrm{X}=$ Jumlah skor butir $(X)$

$\mathrm{Y}=$ Jumlah skor variabel $(\mathrm{Y})$

$\mathrm{X}_{2}=$ Jumlah skor butir $(X)$ kuadrat

$\mathrm{Y}_{2}=$ Jumlah skor variabel $(\mathrm{Y})$ kuadrat

$X Y=$ Jumlah perkalian skor butir $(X)$ dan skor variabel $(\mathrm{Y})$

Menghitung korelasi bagian total adapun rumus untuk menghitung korelasi bagian total adalah sebagai berikut :

$$
\mathrm{r}_{\mathrm{bt}}=\frac{r_{x y}\left(S B_{y}\right)-S B_{x}}{\sqrt{\left\{\mathrm{SB}_{\mathrm{x}}^{2}+\mathrm{SB}_{\mathrm{y}}^{2}-2\left(\mathrm{r}_{\mathrm{xy}}\right)\left(\mathrm{SB}_{\mathrm{x}}\right)\left(\mathrm{SB}_{\mathrm{y}}\right)\right\}}}
$$

dengan:

$\mathrm{r}_{\mathrm{bt}}=$ Koefisien korelasi bagian total

$r_{x y}=$ Koefisien korelasi sederhana

$\mathrm{N}=$ Jumlah responden uji coba

$\mathrm{SB}_{\mathrm{x}}=$ Deviasi standar skor butir

$\mathrm{SB}_{\mathrm{y}}^{\mathrm{x}}=$ Deviasi standar skor variabel

$$
\sqrt{\frac{\sum X^{2}-\left(\sum X\right)^{2} N}{N-1}}
$$

Penyajian hipotesis Untuk menguji hipotesa pertama digunakan rumus:

$$
\mathrm{Y}=\beta_{0}+\beta_{1} X_{i}+\beta_{2} X_{2}+e
$$

dengan:

$\mathrm{Y}_{1}=$ Motivasi peternak membangun teknologi biogas

$X_{1}=$ Respon peternak terhadap LPTP (Lembaga Pembangunan Teknologi Pedesaan)

$\mathrm{X}_{2}=$ Respon tetangga terhadap teknologi biogas

$\beta_{0}=$ Konstanta

$\beta_{1 .} . \beta_{9}=$ Koefisien regresi

$\mathrm{e}=$ Kesalahan pengganggu 


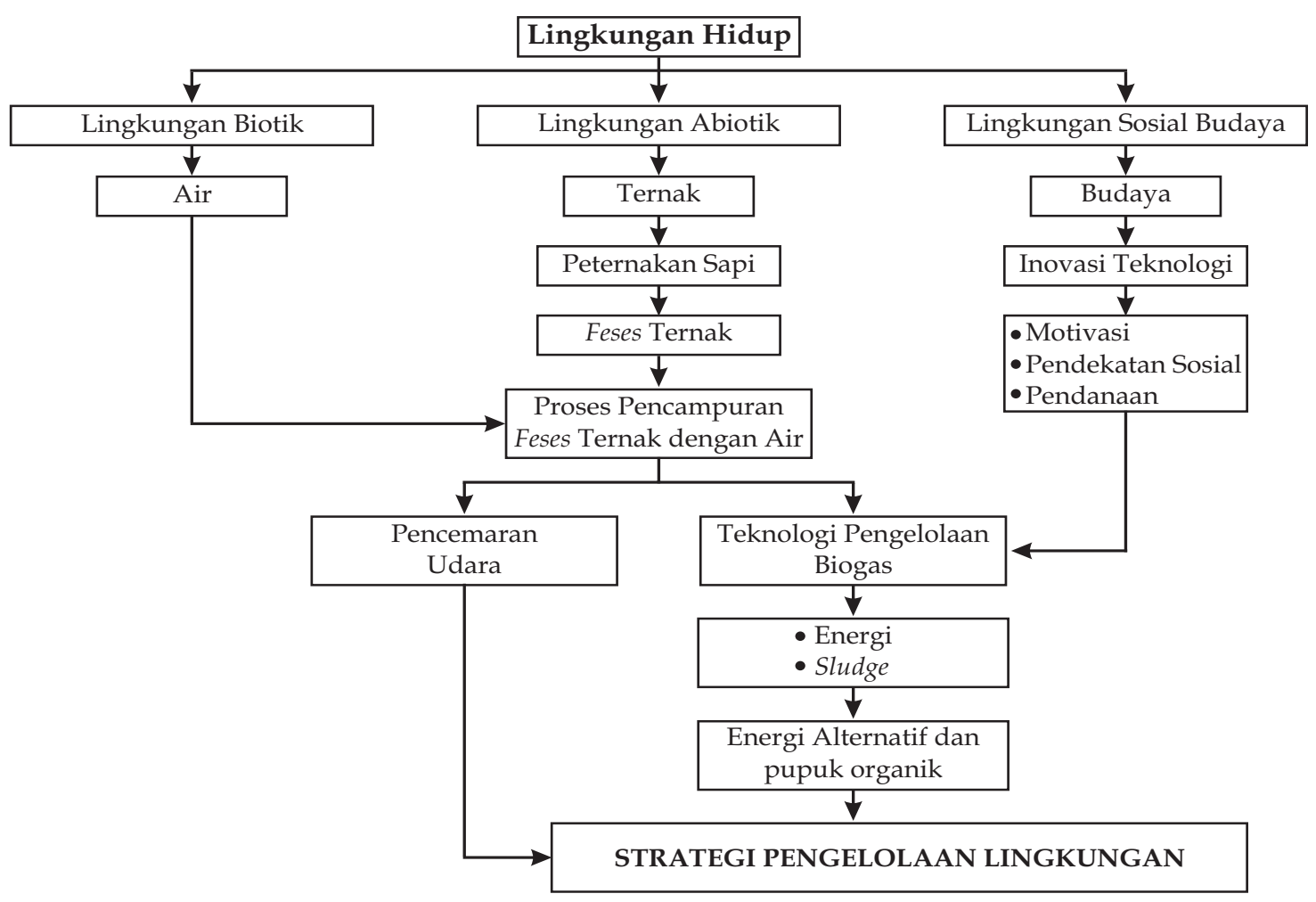

Gambar 1.

Diagram Alir Penelitian

\section{PEMBAHASAN \\ Analisis Faktor-Faktor Berpengaruh terhadap Motivasi Peternak dalam Membangun Teknologi Biogas}

Analisis faktor-faktor yang berpengaruh terhadap motivasi peternak dalam membangun teknologi biogas adalah umur, tingkat pendidikan, jumlah anggota keluarga, jumlah ternak sapi, dan respon peternak terhadap Lembaga Pembangunan Teknologi Pedesaan (LPTP), yaitu lembaga swadaya masyarakat yang memperkenalkan pembangunan teknologi biogas yang bekerjasama dengan pemerintah/ instansi yang terkait dan PT. Sari Husada (perusahan susu SGM), serta respon tetangga terhadap pembangunan teknologi biogas.

Tujuan peternak dalam membangun teknologi biogas yaitu ingin memanfaatkan feses ternak sapi sebagai energi alternatif biogas, untukmenghematkayu bakar, minyak tanah dan gas LPG, meminimalkan dampak pencemaran lingkungan, meningkatkan unsur hara tanah di lingkungan sekitar (pekarangan) serta membantu penghematan pengeluaran untuk kebutuhan rumah tangga. Hal ini dikarenakan pada daerah ini, untuk dapat memperoleh kayu bakar harus mencari kayu dengan jarak yang agak jauh serta terlihat dari efesiensi waktu sangat boros sehingga dapat menghabiskan banyak waktu yang digunakan untuk mempersiapkan perapian. Selain itu pemanfaatkan feses ternak sapi sebagai pupuk organik dapat meningkatkan unsur hara tanah yang menunjang pemupukan produk pertanian khususnya pada nutrisi ternak yaitu hijauan makanan ternak dan sebagiannya diperdagangkan.

\section{Umur}

Umur sangat berpenganruh terhadap perilaku seseorang. Baik terhadap kreativitas, responsibilitas dalam inovasi teknologi yang baru. Pengelompokan umur responden di- 
bagi menjadi tiga kelas, yaitu kelas "muda" (<36 tahun), " usia menengah" (36-50 tahun), dan "tua" (>50 tahun).

Tabel 1

Faktor Umur dari Motivasi Peternak dalam Membangun Teknologi Biogas

\begin{tabular}{l|l|l|l}
\hline No. & $\begin{array}{c}\text { Kategori } \\
\text { Umur (Thn) }\end{array}$ & $\begin{array}{c}\text { Frekuensi } \\
\text { Umur }\end{array}$ & $\begin{array}{c}\text { Prosentase } \\
(\mathbf{\%})\end{array}$ \\
\hline 1. & $<36$ & 11 & 43.3 \\
\hline 2. & $36-50$ & 13 & 36.36 \\
\hline 3. & $>50$ & 6 & 2 \\
\hline
\end{tabular}

Berdasarkan tabel 1, memperlihatkan bahwa umur peternak cukup bervariasi, tetapi secara keseluruhan tampak bahwa peternak yang membangun teknologi biogas pada usia menengah yaitu 36-50 tahun tampak lebih besar, sebesar $43.33 \%$ sedangkan peternak dengan usia muda ( $<36$ tahun ) 36,67\%, dan usia tua ( $>50$ tahun) $2 \%$. Hal ini menunjukan bahwa sebagian besar peternak tergolong usia produkif, sehingga berpotensi besar untuk berperan serta dalam membangun teknologi biogas.

\section{PENDIDIKAN}

Tingkat pendidikan dalam penelitian ini adalah tingkat pendidikan formal yang pernah ditempuh oleh peternak. Secara umum dapat dilihat bahwa semakin tinggi tingkat pendidikan, maka semakin luas pengetahuan dan wawasannya tentang pembangunan, sehingga berpengaruh juga terhadap kesadaran tentang pentingnya pembangunan. Untuk lebih jelas dapat dilihat pada tabel 2 berikut ini:

Tabel 2

Faktor Pendidikan dari Motivasi Peternak dalam Membangun Teknologi Biogas

\begin{tabular}{l|l|l|l}
\hline No. & \multicolumn{1}{|c|}{$\begin{array}{c}\text { Tingkat } \\
\text { Pendidikan }\end{array}$} & Frekuensi & $\begin{array}{c}\text { Prosentase } \\
(\mathbf{\%})\end{array}$ \\
\hline 1. & Tidak Tamat SD & 2 & 6.67 \\
\hline 2. & SD & 7 & 23.33 \\
\hline 3. & SMP & 10 & 33.33 \\
\hline 4. & SMA & 10 & 33.33 \\
\hline 5. & Perguruan Tinggi & 1 & 3.33 \\
\hline Jumlah & $\mathbf{3 0}$ & $\mathbf{1 0 0}$ \\
\hline
\end{tabular}

Berdasarkan tabel 2, menunjukan bahwa peternak dengan tingkat pendidikan SMP dan SMA mempunyai jumlah paling tinggi dengan jumlah yang sama, yaitu sebesar $33.33 \%$ sedangkan tamat SD sebesar $23.33 \%$, tidak tamat SD sebanyak $6.67 \%$, dan dari perguruan tinggi sebanyak $3.33 \%$. Dari uraian di atas menggambarkan bahwa tingkat pendidikan para peternak masih dikategorikan rendah. Hal itu dapat dipengaruhi oleh kemampuan sosial ekonomi.

\section{Jumlah Anggota Keluarga}

Konsep ini semakin menunjukkan bahwa jumlah anggota keluarga berkaitan erat dengan aspek sosial ekonomi rumah tangga. Dari aspek sosial, banyaknya anggota rumah tangga dapat menjadi kebanggaan keluarga karena anggota keluarganya dapat memberikan partisipasi dalam kehidupan bermasyarakat di pedesaan. Pada bidang ekonomi, banyaknya anggota keluarga dapat dipergunakan sebagai modal, khususnya dalam hal tenaga kerja pada sektor petanian khususnya dalam aktivitas peternakan. Adapun banyaknya anggota keluarga yang menjadi tanggungan dalam rumah tangga dan pengaruhnya terhadap motivasi peternak dalam membangun teknologi biogas dapat dilihat pada tabel 3 sebagai berikut ini.

Tabel 3

Faktor Jumlah Anggota Keluarga dari Motivasi Peternak dalam Membangun Teknologi Biogas

\begin{tabular}{l|l|l|l}
\hline No. & $\begin{array}{c}\text { Kategori Jumlah } \\
\text { Anggota Keluarga }\end{array}$ & Frekuensi & $\begin{array}{c}\text { Prosentase } \\
(\mathbf{0})\end{array}$ \\
\hline 1. & $<4$ & 16 & 53.33 \\
\hline 2. & $4-5$ & 12 & 40.00 \\
\hline 3. & $>5$ & 2 & 6.67 \\
\hline Jumlah & $\mathbf{3 0}$ & $\mathbf{1 0 0}$ \\
\hline
\end{tabular}

Berdasarkan tabel 3, menunjukkan bahwa peternak dengan jumlah tanggungan keluarga yang < 4 sebesar 53,33\%, kemudian pada keluarga dengan jumlah tanggungan 4-5 sebanyak $40 \%$, dan peternak dengan tanggungan $>5$ sebanyak 6,67 \% . Hal ini 
menunjukkan bahwa para peternak sudah memahami pentingnya program keluarga berencana guna kesejahteraan keluarga.

\section{Pengalaman Berternak}

Mayoritas penduduk di lokasi penelitian bermata pencaharian di sektor peternakan, hal ini mendorong para peternak bermotivasi untuk meningkatkan pengetahuan dalam mengelolah usaha peternakan kearah yang lebih modern. Oleh karena itu, pengalaman dapat membentuk seseorang untuk memiliki kemampuan serta matang dalam pengambilan keputusan terhadap inovasi yang mendukung keberlanjutan usahanya tersebut. Untuk lebih jelas mengenai pengalaman para peternak dapat dilihat pada tabel 4 berikut ini.

Tabel 4

Faktor Pengalaman Berternak dari Motivasi Peternak dalam Membangun Teknologi Biogas

\begin{tabular}{l|l|l|l}
\hline No. & $\begin{array}{c}\text { Pengalaman } \\
\text { Beternak (Thn) }\end{array}$ & Frekuensi & $\begin{array}{c}\text { Prosentase } \\
(\mathbf{\%})\end{array}$ \\
\hline 1. & $<5$ & 9 & 30.00 \\
\hline 2. & $5-10$ & 16 & 53.33 \\
\hline 3. & $>10$ & 5 & 16.67 \\
\hline
\end{tabular}

Berdasarkan tabel 4, menunjukkan bahwa pengalaman beternak yang terlama $>10$ tahun sebesar $16.67 \%$. Selanjutnya pengalaman 5 sampai 10 tahun beternak merupakan prosentase tertinggi sebesar $53.33 \%$, dan pengalaman beternak di bawah dari 5 tahun sebesar 30\%. Dapat diinterpertasikan bahwa pengaruh topografi lingkungan Desa Kepuharjo dan Umbulharjo yang memiliki iklim dingin sangat mendukung pengembangan usaha sapi perah.

\section{Analisis Kajian Faktor-Faktor Keper- luan Hidup/ Sosial Ekonomi Peternak Sebelum dan Sesudah Membangun Teknologi Biogas}

Analisis kajian faktor-faktor keperluan hidup/ sosial ekonomi peternak sebelum dan sesudah membangun teknologi biogas.
Analisis yang dilakukan menggunakan analisis regresi linier dan berganda uji korelasi dan analisis regresi linier berganda dan uji beda dengan menggunakan program SPSS versi 16.0 terbaru dengan fasilitas komputer Uji statistik yang digunakan adalah regresi linier berganda dengan tingkat kemaknaan $\mathrm{P}<0,05$. Berikut adalah menghitung nilai regresi.

\section{Respon Positif terhadap Pemanfaatan Feses Ternak sebagai Energi Alternatif Biogas Berpengaruh terhadap Motivasi Peternak}

Hasil perhitungan mengenai nilai regresi dari pengolahan dengan menggunakan program SPSS di dapat hasil seperti pada tabel 5 berikut:

Tabel 5

Analisis Regresi Ganda dengan Menggunakan Model Summary

Model Summary

\begin{tabular}{l|c|l|l|l}
\hline Model & $\mathbf{R}$ & $\begin{array}{c}\text { R } \\
\text { Square }\end{array}$ & $\begin{array}{c}\text { Adjusted } \\
\text { R Square }\end{array}$ & $\begin{array}{l}\text { Std. Error of } \\
\text { the Estimate }\end{array}$ \\
\hline 1 & $.701^{\mathrm{a}}$ & .491 & .453 & 1.821 \\
\hline
\end{tabular}

a. Predictors: (Constant), X2 Respon tetangga terhadap teknologi Biogas, X1 Respon peternak terhadap LPTP

Berdasarkan hasil tabel 5, model summary pengolahan data dapat diartikan bahwasanya terdapat nilai $\mathrm{R}^{2}$ (determinasi) sebesar 0,491 atau 49,1\%, dari hasil yang ada selanjutnya dilakukan perhitungan dengan analisis anova seperti yang terlihat pada tabel 6 sebagai berikut:

Tabel 6

Hasil Anova Hubungan antara Motivasi Peternak (Y) dengan Respon Peternak Terhadap LPTP $\left(X_{1}\right)$

ANOVA $^{\text {b }}$

\begin{tabular}{l|l|l|l|c|c}
\hline Model & $\begin{array}{c}\text { Sum of } \\
\text { Squares }\end{array}$ & df & $\begin{array}{c}\text { Mean } \\
\text { Square }\end{array}$ & f & Sig. \\
\hline 1. Regression & 86.365 & 2 & 43.183 & 13.027 & $.000^{\mathrm{a}}$ \\
$\begin{array}{l}\text { Residual } \\
\text { Total }\end{array}$ & 89.501 & 27 & 3.315 & & \\
\hline
\end{tabular}

a. Predictors: (Constant), X2 Respon tetangga terhadap teknologi Biogas, X1 Respon peternak terhadap LPTP

b. Dependent Variable: Y Motivasi peternak membangun teknologi Biogas 


\section{LATIFAH HANUM DAMANIK, ADI HERU HUSODO, DAN TOTOK GUNAWAN PEMANFAATAN FESES TERNAK SAPI SEBAGAI ENERGI ALTERNATIF BIOGAS BAGI RUMAH TANGGA DAN DAMPAKNYA TERHADAP LINGKUNGAN}

Berdasarkan hasil analisis anova, maka didapat nilai $\mathrm{F}$ hitung adalah sebesar 13,027, hal ini mengandung arti bahwasanya terdapat hubungan yang signifikan antara motivasi peternak dengan respon peternak terhadap LPTP, hal itu terbukti dengan nilai $\mathrm{P}=0,00$, yang nilainya lebih kecil dari $\mathrm{P}=0,05$, kemudian diperoleh nilai coefficien pada tabel 7 berikut :

Tabel 7

Nilai Koefisien Regresi Linier antara Motivasi Peternak (Y) dengan Respon Peternak terhadap LPTP (X

\section{Coefficients}

\begin{tabular}{|c|c|c|c|c|c|c|}
\hline \multirow{2}{*}{\multicolumn{2}{|c|}{ Model }} & \multicolumn{2}{|c|}{$\begin{array}{c}\text { Unstandardized } \\
\text { Coefficient }\end{array}$} & \multicolumn{2}{|c|}{$\begin{array}{c}\text { Standardized } \\
\text { Coefficient }\end{array}$} & \multirow[t]{2}{*}{ Sig. } \\
\hline & & B & Std. Error & Beta & $\mathbf{t}$ & \\
\hline \multirow[t]{3}{*}{1} & (Constant) & .805 & 6.019 & & .134 & .895 \\
\hline & X1 Respons Peternak terhadap LPTP & .371 & .153 & .334 & 2.423 & .022 \\
\hline & X2 Respons Tetangga terhadap teknologi Biogas & .586 & .139 & .582 & 4.213 & .000 \\
\hline
\end{tabular}

b. Dependent Variable: Y Motivasi peternak membangun teknologi Biogas

Berdasarkan tabel 7, menunjukkan bahwa terdapat nilai $\mathrm{t}$ hitung untuk respon peternak terhadap LPTP adalah sebesar 2, 423 dengan nilai $\mathrm{P}=0.022$. Terdapat nilai $\mathrm{t}_{\text {hitung }}$ untuk respon tetangga terhadap teknologi biogas adalah sebesar 4,213 dengan nilai $\mathrm{P}=$ 0.00. Dari hasil kedua P kedua variable terikat

Tabel 8

Nilai Korelasi Koefisien Regresi Linier antara Motivasi Peternak (Y) dengan Respon Peternak terhadap LPTP $\left(X_{1}\right)$ dan Respon Tetangga terhadap Teknologi Biogas $\left(X_{2}\right)$

Correlation

\begin{tabular}{lllll}
\hline & & $\begin{array}{c}\text { X1 Respons } \\
\text { Peternak terhadap } \\
\text { LPTP }\end{array}$ & $\begin{array}{c}\text { X2 Respons } \\
\text { Tetangga terhadap } \\
\text { teknologi Biogas }\end{array}$ & $\begin{array}{c}\text { Y Motivasi Peter- } \\
\text { nak Membangun } \\
\text { teknologi Biogas }\end{array}$ \\
\hline $\begin{array}{l}\text { X1 Respons } \\
\begin{array}{l}\text { Peternak terhadap } \\
\text { LPTP }\end{array}\end{array}$ & Pearson Corrlation & 1 & .105 & $.396^{*}$ \\
& Sig. (2-tailed) & $\mathrm{N}$ & .580 & .030 \\
X2 Respons & Pearson Corrlation & .105 & 30 & 30 \\
Tetangga terhadap & Sig. (2-tailed) & .580 & 1 & $.617^{*}$ \\
teknologi Biogas & $\mathrm{N}$ & 30 & & .000 \\
& Pearson Corrlation & $.396^{*}$ & 30 & 30 \\
Y Motivasi Peter- & & $.617^{* *}$ & 1 \\
nak Membangun & Sig. (2-tailed) & .030 & .000 & 30 \\
teknologi Biogas & $\mathrm{N}$ & 30 & 30 & \\
\hline
\end{tabular}

* Correlation is significant at the 0.05 level (2-tailed). ${ }^{* *}$ Correlation is significant at the 0.01 level (2-tailed).

Berdasarkan tabel 8, menunjukkan bahwa korelasi didapatkan dari nilai korelasi antara motivasi peternak membangun teknologi biogas dengan respon peternak terhadap LPTP dengan nilai $r$ sebesar 0,396, ini berarti menunjukan bahwasanya ada yaitu respon peternak terhadap LPTP dan respon tetangga terhadap teknologi biogas masing-masing menunjukkan nilai yang signifikan terhadap motivasi peternak. Dari hasil analisis uraian di atas, maka diperoleh hasil : $Y=0,805+0,371 X_{1}+0,586 X_{2}$ 
bahwasanya ada hubungan yang signifikan (kuat) antara kedua variabel tersebut.

\section{Analisis Perbedaaan Penghematan Pengeluaran Keperluan Rumah Tangga}

Berdasarkan hasil analisis terdapat perbedaaan pada penghematan pengeluaran keperluan rumah tangga. Analisis mengenai perbedaan pada nilai penghematan pengeluaran keperluan rumah tangga sebelum dan sesudah, dianalisis dengan menggunakan uji T. Untuk lebih jelas lagi dapat dilihat pada tabel 9 di bawah ini :

Tabel 9.

Nilai Penghematan Pengeluaran Biogas Sebelum dan Sesudah

Paired Samples Statistics

\begin{tabular}{llccll}
\hline & & Mean & N & Std. Deviation & Std. Error Mean \\
\hline \multirow{2}{*}{ Pair 1 } & Penghematan Pengeluaran Biogas-Sesudah & 52.70 & 30 & 5.978 & 1.091 \\
& Penghematan Pengeluaran Biogas-Sebelum & 50.20 & 30 & 6.305 & 1.151 \\
\hline
\end{tabular}

Berdasarkan hasil tabel 9, menunjukkan adanya gambaran nilai pengeluaran sebelum adanya penghematan energi rumah tangga

Tabel 10.

Nilai Penghematan Pengeluaran Biogas Sebelum dan Sesudah dengan Menggunakan Uji T

Paried Samples Test

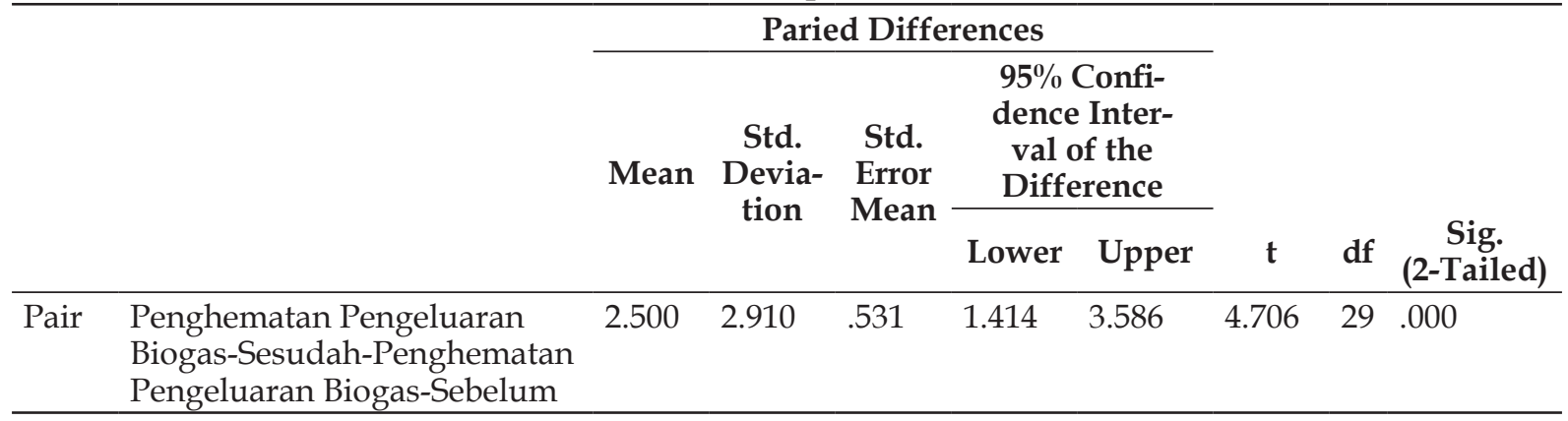

Analisis perhitungan dengan menggunakan uji $\mathrm{T}$ pada pada nilai penghematan biogas baik sebelum dan sesudah di dapatkan nilai $\mathrm{T}_{\text {hitung }}$ sebesar 4,706 (30-1), dengan nilai $\mathrm{P}$ adalah 0,00, ini menunjukkan bahwa terdapat nilai perbedaan yang singnifikan antar sebelum dan sesudah ada penghematan terhadap penggunaan biogas di rumah tangga karena ditandai dengan nilai $\mathrm{P}<0,05$.

\section{SIMPULAN}

Berdasarkan uraian yang telah disampaikan di atas, mengenai pemanfaatan feses ternak sapi sebagai energi alternatif biogas bagi rumah tangga dan dampaknya sebesar 50,20 $\mathrm{m}^{3}$, namun sesudah terdapat nilai pengeluaran sebesar $52,70 \mathrm{~m}^{3}$. terhadap lingkungan di Desa Kepuharjo, Kecamatan Cangkringan, Kabupaten Sleman, maka dapatlah diambil kesimpulan sebagai berikut: respon yang positif terhadap pemanfaatan feses ternak sebagai energi alternatif biogas berpengaruh terhadap motivasi peternak dapat terbukti ditandai dengan adanya nilai $t$ hitung untuk respon peternak terhadap LPTP adalah sebesar 2, 423 dengan nilai $\mathrm{P}=0.022$, begitu juga dengan nilai $\mathrm{t}_{\text {hitung }}$ untuk respon tetangga terhadap teknologi biogas adalah sebesar 4,213 dengan nilai $\mathrm{P}=0.00$, dari kedua variabel terikat yaitu respon peternak terhadap LPTP dan respon tetangga terhadap teknologi biogas masing-masing menunjukkan nilai yang 


\section{LATIFAH HANUM DAMANIK, ADI HERU HUSODO, DAN TOTOK GUNAWAN PEMANFAATAN FESES TERNAK SAPI SEBAGAI ENERGI ALTERNATIF BIOGAS BAGI RUMAH TANGGA DAN DAMPAKNYA TERHADAP LINGKUNGAN}

signifikan terhadap motivasi peternak; hal itu disebabkan nilai kedua variabel terikat $\mathrm{P}<$ 0,05. Hasil analisis penghematan biogas baik sebelum dan sesudah didapatkan nilai $\mathrm{T}_{\text {hitung }}$ sebesar 4,706 (30-1), dengan nilai $\mathrm{P}$ adalah 0,00 , ini menunjukkan bahwa terdapat nilai perbedaan yang signifikan antar sebelum dan sesudah ditandai dengan ada penghematan terhadap penggunaan biogas di rumah tangga dengan nilai $\mathrm{P}<0,05$, selain itu juga terdapat nilai pengeluaran sebelum adanya penghematan energi rumah tangga sebesar $50,20 \mathrm{~m}^{3}$, tetapi sesudah terdapat nilai pengeluaran sebesar $52,70 \mathrm{~m}^{3}$ hal ini berarti setelah dilakukan penghematan terhadap pemanfaatan energi biogas sebesar 2,50 $\mathrm{m}^{3}$

\section{DAFTAR PUSTAKA}

Djaja W(2008) Langkah Jitu Membuat Kompos dari Kotoran Ternak dan Sampah. Jakarta: PT. Agro Media Pustaka.

Hadi N (1980) Pemanfaatan Biogas sebagai Sumber Energy Non Konvensional dan
Pengembangan Desa. Jakarta: Pusat Pengembangan Teknologi Minyak dan Gas Bumi.

Hadi S (1991) Statistik Jilid I. Yogyakarta: Andi Offset.

Hariadi U (2005) Respon Masyarakat terhadap Rencana Pembangunan Kawasan Wisata Energi Alternatif. Yogyaakarta: Universitas Gadjah Mada.

Said S (2008) Biogas dari Kotoran Hewan. Jakarta: Indocamp.

Sugiyono (2008) Metode Penelitian Kuantitatif, Kualitatif dan RED. Jakarta: Alfabeta.

Undang-Undang Republik Indonesia No. 32 tahun 2009 tentang Perlindungan dan Pengelolaan Lingkung, Kementrian Lingkungan Hidup, Jakarta

Wahyuni S (2008) Biogas. Jakarta: Penebar Swadaya. 